Bull. Chem. Soc. Ethiop. 2012, 26(3), 395-405.

Printed in Ethiopia

ISSN 1011-3924

DOI: http://dx.doi.org/10.4314/bcse.v26i3.8

(C) 2012 Chemical Society of Ethiopia

\title{
INTERACTION MODE BETWEEN METHYLENE BLUE-Sm(III) COMPLEX AND HERRING SPERM DNA
}

\author{
Ya-min $\mathrm{Hu}^{1}$, Xing-ming Wang ${ }^{1 *}$, Hai-zhuan Pan ${ }^{1}$ and Li-sheng Ding ${ }^{2}$ \\ ${ }^{1}$ Department of Chemistry, School Materials Science and Engineering, Southwest University of \\ Science and Technology, Mian Yang 621010, China \\ ${ }^{2}$ Chengdu Institute of Biology, Chinese Academy of Sciences, Chengdu 610041, China
}

(Received July 8, 2011; revised March 16, 2012)

\begin{abstract}
Spectroscopic and viscosity methods were applied to investigate the interaction between methylene blue (MB)-Sm(III) complex and herring sperm DNA by using acridine orange as a spectral probe in Tris-HCl buffer ( $\mathrm{pH}$ 7.40). By means of molar ratio method, the binding

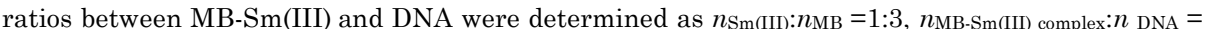

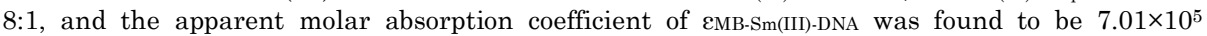
$\mathrm{M}^{-1} \mathrm{~cm}^{-1}$. The bonding constants at different temperatures $K^{\theta}{ }_{292 \mathrm{~K}}=7.35 \times 10^{5} \mathrm{M}^{-1}, K^{\theta}{ }_{310 \mathrm{~K}}=1.25 \times 10^{5}$ $\mathrm{M}^{-1}$ were obtained by double reciprocal method. Thermodynamic function computation demonstrates that $\Delta_{\mathrm{r}} S_{\mathrm{m}}{ }^{\ominus}$ is the primary driving power of the interaction between MB-Sm(III) and herring sperm DNA. By combination analysis of the Scatchard method, circular dichroism spectroscopy and viscosity method, it suggests that the interaction mode between MB-Sm(III) complex and herring sperm DNA are a mixed binding, which contains partial intercalation and electrostatic interaction.
\end{abstract}

KEY WORDS: Methylene blue-Sm(III), Complex, Herring sperm DNA, Interaction

\section{INTRODUCTION}

Studies of the interaction between rare earth metal complexes and DNA have been a subject of interest in bioinorganic chemistry, especially since the discovery of cisplatin and their analogues. These studies have been useful for the development and the comprehension of the activity of new chemotherapeutic agents designed for the treatment of numerous diseases [1-3]. These metal complexes (such as $\mathrm{La}(\mathrm{III}), \mathrm{Ce}(\mathrm{III}), \mathrm{Pt}(\mathrm{II})$ and $\mathrm{Pd}$ ( II ) complex) are known to bind to DNA by a series of non-covalent interactions, such as intercalation, electrostatic force and groove interaction $[4,5]$. Some studies show, by forming intercalation complexes with DNA, many of these chemotherapeutic agents inhibit the synthesis of the deoxyribonucleic acid by intercalation, groove-face binding or external electrostatic binding or a covalent interaction [68].

Methylene blue (MB) (Figure 1) is a phenothiazinyl dye, which is a kind of photosensitizer drug molecules showing promising applications in the photodynamic therapy (PDT) for anticancer treatment. Due to its planar structure, which is similar to acridine dyes, MB can interact easily with DNA and has been used as an optical probe in biophysical systems [9]. Many years of research indicated that rare-earth complexes have good antibacterial and antiviral activity in pharmacology, especially Sm [10-13]. In addition, their toxicities are decreased after coordinating with a ligand [14]. The interaction of methylene blue with DNA has been studied with various methods $[15,16]$. However, investigation about the interaction between MBSm(III) complex and herring sperm DNA has not been reported. The studies of interactions between rare earth metal complexes of MB with DNA are important to further understand the pharmacology of MB.

*Corresponding author. E-mail: xmwang_xkd@yahoo.com.cn 


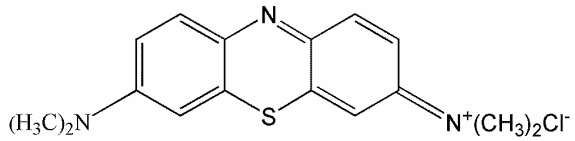

Figure 1. The structure of methylene blue.

In this paper, we synthesized the novel MB-Sm(III) complex which was characterized by IR spectrum, elemental analysis and mass spectrum. The interaction between MB-Sm(III) complex and herring-sperm DNA (hsDNA) has been investigated with the aid of the acridine orange (AO) spectral probe, by UV-Vis absorption and fluorescence spectroscopy, viscosity measurements, circular dichroism spectroscopy [17, 18]. It would be helpful to further understand the mechanism of interactions between DNA and MB-Sm(III) complexes as well as further understand methylene blue's pharmacological effects. The knowledge gained from this study should be valuable for the development of potential probes for DNA structure and new cancer therapeutic reagents. Herring sperm DNA is used in this work because it is different from what most researchers are studying, such as calf thymus DNA, and also due to its minimal cross-reactivity and availability.

\section{EXPERIMENTAL}

\section{Materials}

All of the samples were dissolved in Tris- $\mathrm{HCl}$ buffer, the concentrations of Tris was $0.10 \mathrm{M}$ by adding $\mathrm{HCl}$ solution, whose concentration was $0.10 \mathrm{M}$, then the $\mathrm{pH}$ was recorded on a $\mathrm{pHS}-2 \mathrm{C}$ acidometer, Fangzhou Technology Company, China) examined the $\mathrm{pH}$ of the buffer until the value reached 7.40. $\mathrm{Sm}_{2} \mathrm{O}_{3}(99.99 \%)$ was purchased from Beijing Fangzheng Rare Metal Lab Company, and dissolved in dense $\mathrm{HCl}$, then we vaporized $\mathrm{HCl}$ slowly to get $\mathrm{SmCl}_{3}$ solution in different concentrations. Acridine orange (99.7\%) and methylene blue $(99.7 \%)$ were purchased from Shanghai China Medicine Chemical Plant. Other reagents were at least analytical grade, and were used without further purification.

\section{Apparatus and procedure}

The MB-Sm(III) complex was prepared by concentrating stoichiometric samarium chloride and $\mathrm{MB}$ in water, recirculated on the water bath at $313 \mathrm{~K}$ for $10 \mathrm{~h}$, and then yielded precipitation after standing several days. The sample was washed by water and dried in oven, after several hours precipitation of MB-Sm(III) complex was achieved. The IR spectra $\left(400-4000 \mathrm{~cm}^{-1}\right)$ of the complex was recorded as $\mathrm{KBr}$ pellets on Spectrum One FTIR system (PE Company, USA), it display clearly the $v_{\mathrm{C}=\mathrm{N}}$ stretching vibration at $1598 \mathrm{~cm}^{-1}$ and the $v_{\mathrm{C}-\mathrm{N}}$ stretching vibration at $1138 \mathrm{~cm}^{-1}$ [19]. On complexation, the $v_{\mathrm{C}=\mathrm{N}}$ stretching vibration was shifted to higher frequency to $1602 \mathrm{~cm}^{-1}$ and the $v_{\mathrm{C}-\mathrm{N}}$ stretching vibration at $1142 \mathrm{~cm}^{-1}$. It indicates that nitrogen is coordinated to the central ion Sm(III). Carbon, hydrogen, nitrogen and sulfur analyses were obtained using a VARIO EL CUBE (VARIO Company, General), Elemental analysis: C, 44.95; $\mathrm{H}, 5.71 ; \mathrm{N}, 9.81, \mathrm{~S}, 7.48 \%$ (experimental data); C, 43.48; H, 5.44; N, 9.51, S, 7.25\% (theoretical value). We surmised the empirical formula is $\left[\mathrm{C}_{48} \mathrm{H}_{54} \mathrm{C}_{13} \mathrm{~N}_{9} \mathrm{~S}_{3} \mathrm{Sm}\right] \mathrm{Cl}_{3} \cdot 3 \mathrm{H}_{2} 0$. The relative molecular weight is 1320.14 . Gas chromatography mass spectrometry was carried out on a Polaris Ion trap type (USA THERMO FISHER, USA): MS m/z: $1272\left(\mathrm{M}^{+}, 100\right)$, the proposed structure is illustrated in Figure. 2.

The absorption spectra were carried out with an UV-2102 spectrophotometer (Shimadzu Company, Japan). $3.00 \mathrm{~mL}$ solution in $1.00 \mathrm{~cm}$ quartz cells, containing appropriate 
concentration of a certain solution, was titrated by successive additions of another stock solution. Appropriate blanks corresponding to the buffer were used as the reference. The absorption spectral was measured after 5 min.

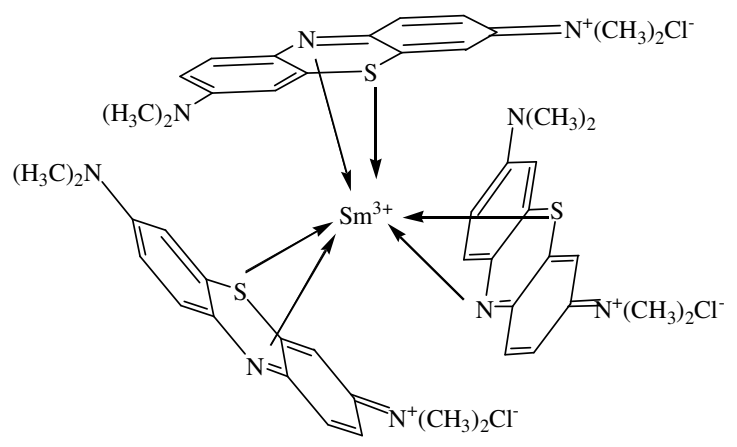

Figure 2. The proposed structure of methylene blue-Sm(III) complex.

The fluorescence spectra were recorded on a FL-4500 spectro fluorophotometer (Shimadzu Company, Japan). $3.00 \mathrm{~mL}$ solution in $1.00 \mathrm{~cm}$ quartz cells, containing appropriate concentration of a certain solution, was titrated by another stock solution. The widths of both the excitation slit and the emission slit were set to $5 \mathrm{~nm}$; and the excite wavelength was set at $411.7 \mathrm{~nm}$. The fluorescence spectra were measured after $5 \mathrm{~min}$.

Measurement of fluorescence Scatchard plots hsDNA was mixed with complex in different molar ratios $\left(\mathrm{C}_{\mathrm{MB}-\mathrm{Sm}(\mathrm{III}) \text { complex }}: \mathrm{C}_{\mathrm{DNA}}=0,0.30,0.600 .90\right)$. After the reaction mixtures were kept in darkness for $30 \mathrm{~min}$, fluorescence titrations were performed by stepwise addition of AO to the above reaction mixtures and the fluorescence intensities were measured at $298 \mathrm{~K}$.

Viscosity experiments were carried out using a viscometer, which was immersed in a thermostat water-bath at room temperature. An appropriate amount of MB-Sm(III) complex was added into the viscometer to give a value of $\mathrm{C}_{\mathrm{MB} \text {-Sm(III) complex }}$ while keeping the DNA concentration constant. The data obtained were presented as $\left(\eta / \eta_{0}\right)^{1 / 3}$ versus $\mathrm{C}_{\mathrm{MB}-\mathrm{Sm} \text { (III) complex }}$, where $\eta$ and $\eta_{0}$ are the viscosity of DNA in the presence and absence of MB-Sm(III) complex, respectively.

Circular dichroism (CD) measurements were recorded on a JASCO-815 spectropolarimeter (Japan Spectroscopic Ltd, Japan). The CD spectroscopy of DNA and MB-Sm(III)-DNA were recorded in the range of $200-450 \mathrm{~nm}$ with a scan rate of $50 \mathrm{~nm} / \mathrm{min}$.

\section{RESULTS AND DISCUSSION}

\section{Interaction between $M B$ and $\operatorname{Sm}(I I I)$}

Figure 3 displays the absorption spectral change of $\mathrm{MB}$ upon addition of $\mathrm{Sm}$ (III) in $\mathrm{pH} 7.40$ Tris- $\mathrm{HCl}$ buffer. The absorption of the system shows clear hypochromicity. Therefore, it can be deduced that there is an interaction between $\mathrm{Sm}$ (III) and MB, so eventually form a MB-Sm(III) complex.

In order to determine the binding ratio of ligand to $\mathrm{Sm}$ (III), the mole ratio method was done at $246 \mathrm{~nm}$. From Figure 4, the binding ratio of of ligand to $\mathrm{Sm}(\mathrm{III})$ is $3: 1$. According to Lambert-Beer law: $A=\varepsilon b c$, the molar apparent absorption coefficient of MB-Sm(III) complex is found to be, $\varepsilon=4.28 \times 10^{4} \mathrm{M}^{-1} \cdot \mathrm{cm}^{-1}$. 


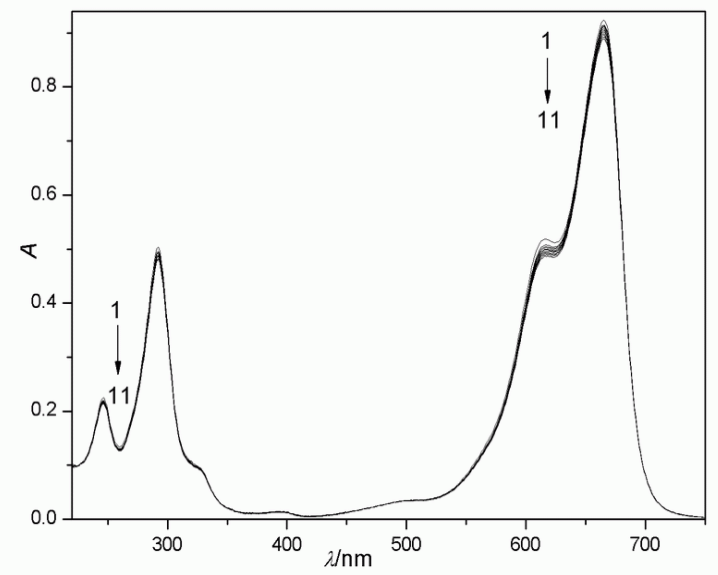

Figure 3. Effect of $\mathrm{Sm}(\mathrm{III})$ on the absorption spectra of $\mathrm{MB}\left(c_{\mathrm{MB}}=3.00 \times 10^{-5} \mathrm{M} ; c_{\mathrm{Sm} \text { (III })}=\right.$ $3.00 \times 10^{-4} \mathrm{M}(20 \mu \mathrm{L}$ per scan 1-11: 0-200 $\left.\mu \mathrm{L})\right)$.

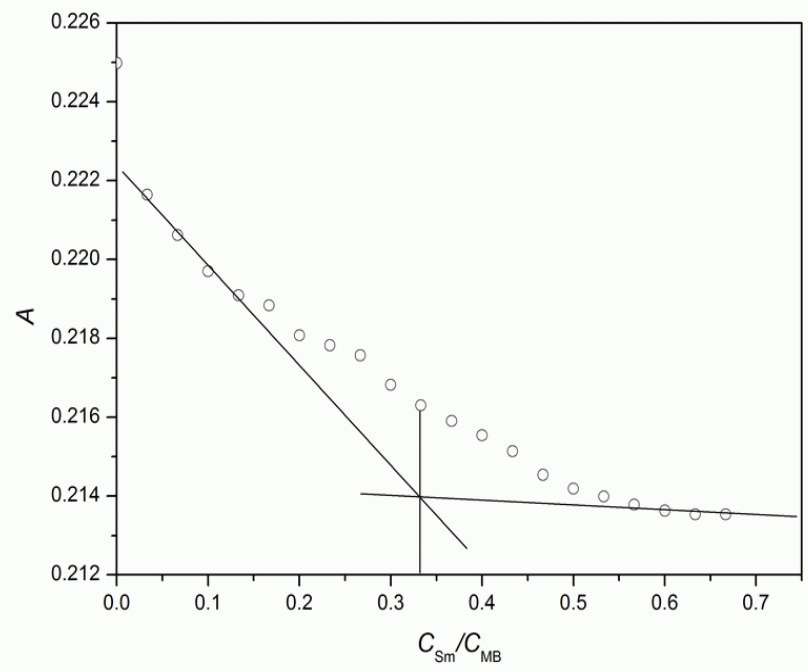

Figure 4. Molar ratio plots of $\mathrm{Sm}(\mathrm{III})-\mathrm{MB}$ system $\left(c_{\mathrm{MB}}=1.50 \times 10^{-5} \mathrm{M}\right)$.

\section{Absorption spectra: $M B-S m(I I I)$ complex interaction with hsDNA}

The absorption spectra of MB-Sm(III) complex are given in Figure 5. With increasing concentration of DNA, the absorption peaks at $292 \mathrm{~nm}, 615 \mathrm{~nm}$ and $665 \mathrm{~nm}$ of MB-Sm(III) complex show clear hypochromicity, without red shift. But the absorption peak at $246 \mathrm{~nm}$ exhibits hyperchromicity. The isosbestic point has been observed at $286 \mathrm{~nm}$. In general, hypochromism and isosbestic points are associated with the binding of the complex to the helix 
by an intercalative mode involving strong stacking interaction of the aromatic chromophore of the complex between the DNA base pairs. However, hyperchromic effect may also be due to the electrostatic interaction between positively charged and the negatively charged phosphate backbone which occurs at the edge of the double helix DNA [20, 21]. The result demonstrates that MB-Sm(III) can bind to DNA by partial intercalation mode and electrostatic binding.

Mole ratio method was also used to determine the binding ratio of MB-Sm(III) with DNA. The binding ratio is shown by Figure 6: $n_{\mathrm{MB}-\mathrm{Sm}(\mathrm{III}) \text { complex }}: n_{\mathrm{DNA}}=8: 1$. According to Lambert-Beer law: $A=\varepsilon b c$, the apparent molar absorption coefficient $\cong$ molar absorptivity, $\varepsilon=7.01 \times 10^{5}$ $\mathrm{M}^{-1} \cdot \mathrm{cm}^{-1}$ is calculated.

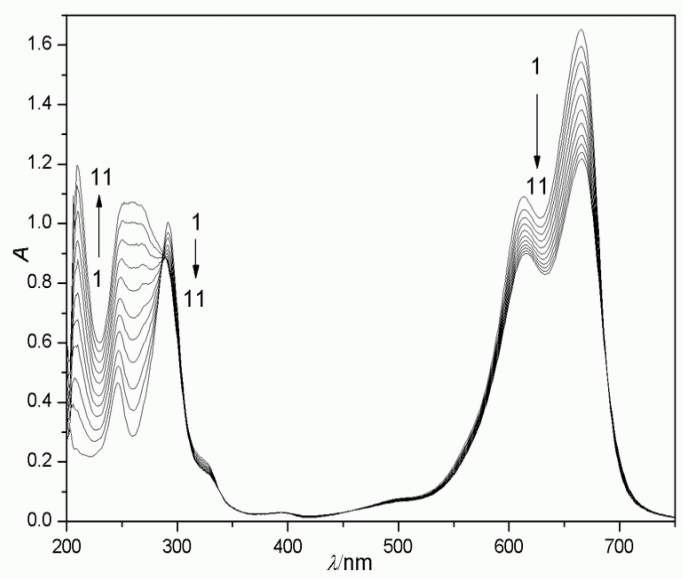

Figure 5. Effect of hsDNA on the absorption spectra of $\mathrm{Sm}(\mathrm{III})(\mathrm{MB})_{3}\left(c_{\mathrm{MB}-\mathrm{Sm}(\mathrm{III})}\right.$ complex $=$ $1.00 \times 10^{-5} \mathrm{M} ; c_{\mathrm{hsDNA}}=3.75 \times 10^{-5} \mathrm{M}(20 \mu \mathrm{L}$ per scan, $\left.1-11: 0-200 \mu \mathrm{L}), \mathrm{T}=292 \mathrm{~K}\right)$.

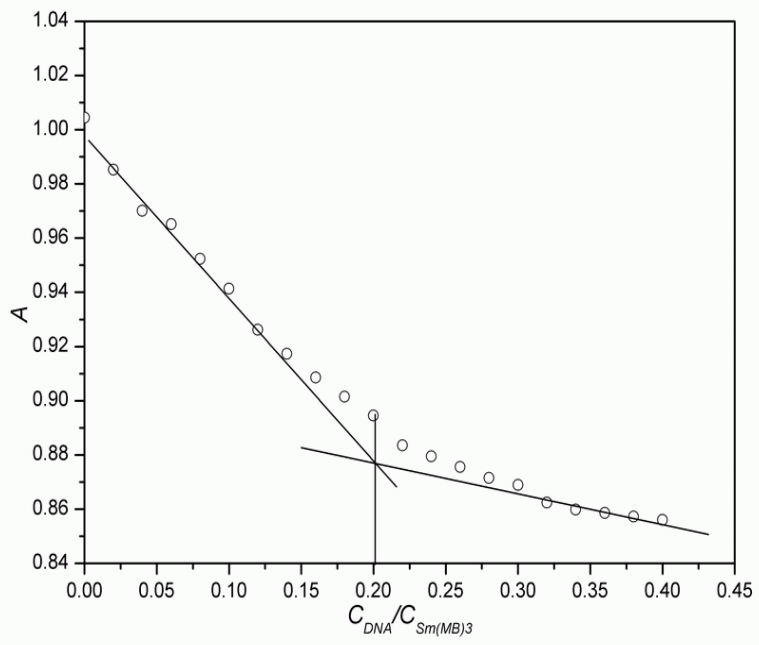

Figure 6. Molar ratio plots of $\mathrm{Sm}(\mathrm{III})(\mathrm{MB})_{3}$-hsDNA system $\left(c_{\mathrm{MB}-\mathrm{Sm}(\mathrm{III}) \text { complex }}=1.00 \times 10^{-5} \mathrm{M}, \mathrm{T}=\right.$ $292 \mathrm{~K})$.

Bull. Chem. Soc. Ethiop. 2012, 26(3) 


\section{Thermodynamic parameters}

In order to see the interaction between MB-Sm(III) complex and hsDNA, the binding constant was determined from the absorption based on the following equation [22, 23]:

$1 /\left(A_{0}-A\right)=1 / A_{0}+1 /\left(K \times A_{0} \times \mathrm{C}_{\mathrm{DNA}}\right)$

where $A_{0}$ is the absorbency of MB-Sm(III) complex in the absence of hsDNA, $A$ is the absorbency of MB-Sm(III) complex in the presence of hsDNA, $K$ is the binding constant between MB-Sm(III) complex and hsDNA, $\mathrm{C}_{\mathrm{hsDNA}}$ is the concentration of hsDNA. The double reciprocal plots of $1 /\left(A_{0}-A\right) \mathrm{vs} .1 / c_{\mathrm{DNA}}$ are linear (at $292 \mathrm{~K}$ and $310 \mathrm{~K}$, respectively) and the association binding constants are calculated (Figure 7): $K^{\theta}{ }_{292 \mathrm{~K}}=7.35 \times 10^{5} \mathrm{M}^{-1}, K^{\theta}{ }_{310 \mathrm{~K}}=1.25 \times 10^{5}$ $\mathrm{M}^{-1}$. According to the relation equation of $K^{\Theta}, \Delta_{\mathrm{r}} H_{\mathrm{m}}{ }^{\ominus}$ and $T$ :

$\ln K_{2}{ }^{\Theta} / K_{1}{ }^{\Theta}=-\Delta_{\mathrm{r}} H_{\mathrm{m}}{ }^{\Theta}\left(1 / T_{2}-1 / T_{1}\right) / R$

where $K_{1}{ }^{\ominus}$ is standard binding constant of MB-Sm(III) complex and DNA at $292 \mathrm{~K}, K_{2}{ }^{\Theta}$ is standard binding constant of $\mathrm{Sm}(\mathrm{III})(\mathrm{MB})_{3}$ and hsDNA at $310 \mathrm{~K}, T_{1}$ is $292 \mathrm{~K}, T_{2}$ is $310 \mathrm{~K}$, $\Delta_{\mathrm{r}} H_{\mathrm{m}}{ }^{\ominus}$ is standard molar reaction enthalpy. Then $\Delta_{\mathrm{r}} H_{\mathrm{m}}{ }^{\ominus}=-7.41 \times 10^{4} \mathrm{~J} \cdot \mathrm{mol}^{-1}$ is deduced. The positive result shows it is an endothermic reaction that temperature enhancement redounded to reaction processes. According to the relation equation of $K^{\Theta}, \Delta_{\mathrm{r}} G_{\mathrm{m}}{ }^{\ominus}$ and $T$ :

$\Delta_{\mathrm{r}} G_{\mathrm{m}}{ }^{\ominus}=-R T \ln K^{\Theta}$

where $\Delta_{\mathrm{r}} G_{\mathrm{m}}{ }^{\Theta}$ refer to the standard molar reaction Gibbs free energy, $T$ is $292 K, K^{\Theta}$ refer to the standard binding constant of MB-Sm(III) complex and DNA in $292 \mathrm{~K}$. Then $\Delta_{\mathrm{r}} G_{\mathrm{m}}{ }^{\ominus}=-7.18 \times 10^{5}$ $\mathrm{J} \cdot \mathrm{mol}^{-1}$ is deduced. The negative result shown the interaction process between MB-Sm(III) complex and hsDNA is spontaneous. According to Gibbs-Helmhotz equation:

$\Delta_{\mathrm{r}} G_{m}{ }^{\ominus}=\Delta_{\mathrm{r}} H_{\mathrm{m}}{ }^{\ominus}-T \Delta_{\mathrm{r}} S_{m}{ }^{\ominus}$

where $\Delta_{\mathrm{r}} S_{m}{ }^{\ominus}$ refer to the standard molar reaction entropy, $T$ is $292 \mathrm{~K}$. Then $\Delta_{\mathrm{r}} S_{m}{ }^{\ominus}=3.66 \times 10^{2}$ $\mathrm{J} \cdot \mathrm{mol}^{-1}, \Delta_{\mathrm{r}} H_{\mathrm{m}}{ }^{\theta}=-7.41 \times 10^{4} \mathrm{~J} \cdot \mathrm{mol}^{-1} \cdot \mathrm{K}^{-1}$ is deduced. The results suggested that $\Delta_{\mathrm{r}} S_{m}{ }^{{ }}$and $\Delta_{\mathrm{r}} H_{\mathrm{m}}{ }^{\theta}$ are the driven force in this reaction, and the mainly factor was $\Delta_{\mathrm{r}} S_{m}{ }^{\theta}$. Because $\Delta_{\mathrm{r}} H_{\mathrm{m}}{ }^{\theta}<0$ and $\Delta_{\mathrm{r}} S_{m}{ }^{\ominus}>0$, DNA-MB-Sm(III) complex is stabilized mainly by static interactions [24].

Competitive interaction of $M B-S m(I I I)$ complex and $A O$ with DNA

Further evidence for the mode of binding between MB-Sm(III) complex and hsDNA is given through the competitive experiment by a fluorescence spectral technique using $\mathrm{AO}$ as probe. $\mathrm{AO}$ was chosen as a representative DNA intercalator because of its known spectral and selfaggregation characteristics, and its wide use as a fluorescence chromophore marker for DNA [25].

Figure 8 illustrates the emission spectra of the hsDNA-AO system in the absence and presence of MB-Sm(III) complex. When the concentration of MB-Sm(III) complex was added, the remarkable fluorescence decrease of hsDNA-AO system was observed at the maximum of $525 \mathrm{~nm}$ and $479 \mathrm{~nm}$. The new peak at the maximum of $684 \mathrm{~nm}$ is the characteristic peak of the MB-Sm(III) complex, and an isosbestic point was observed at the maximum of $645 \mathrm{~nm}$. This phenomenon proves that MB-Sm(III) complex substitutes for AO in the hsDNA-AO system, which led to a large decrease in the emission intensity of the DNA-AO system. The reaction competition of MB-Sm(III) complex with AO is remarkable, hence the mode bonding of hsDNA with MB-Sm(III) complex is intercalation [26, 27]. 


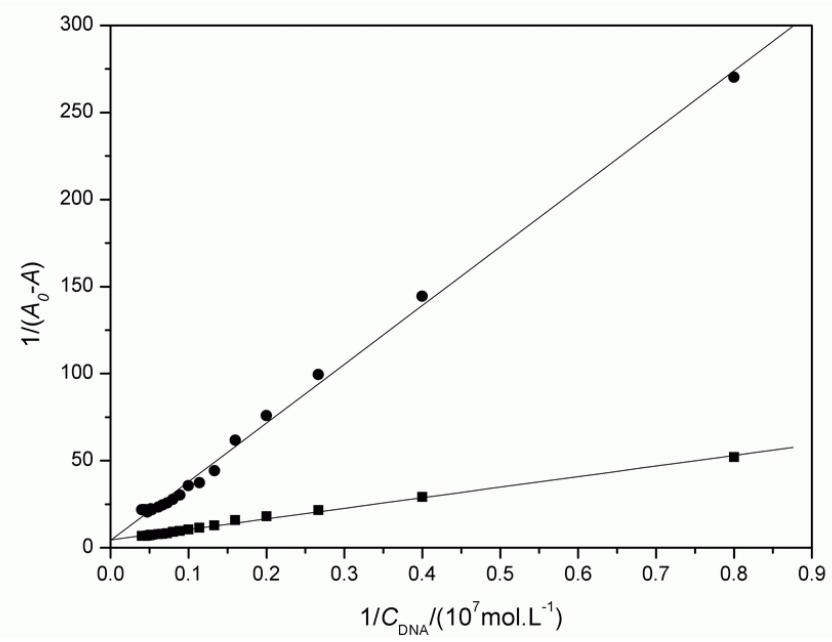

Figure 7. Double reciprocal plot of $\mathrm{Sm}(\mathrm{III})(\mathrm{MB})_{3}$-hsDNA system $(\mathrm{pH}=7.40)$; a.292K; b. $310 \mathrm{~K}$;

$\mathrm{C}_{\mathrm{MB}-\mathrm{Sm}(\mathrm{III}) \text { complex }}=1.00 \times 10^{-5} \mathrm{M} ; \mathrm{T}=292 \mathrm{~K}$ ).

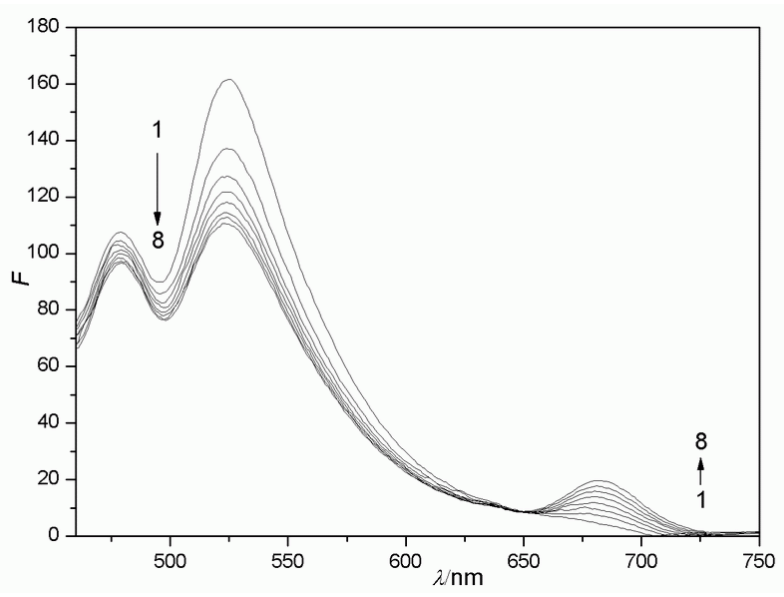

Figure 8. Effect of $\mathrm{Sm}(\mathrm{III})(\mathrm{MB})_{3}$ on the fluorescence spectrum of AO-hsDNA; $\mathrm{C}_{\mathrm{AO}-\mathrm{hsDNA}}=$ $1.00 \times 10^{-7} \mathrm{M}, \mathrm{C}_{\mathrm{MB}-\mathrm{Sm}(\mathrm{III}) \text { complex }}=2.40 \times 10^{-5} \mathrm{M}(10 \mu \mathrm{L}$ per scan, 1-8: 0-70 $\mu \mathrm{L}) \mathrm{T}=292$ $\mathrm{K})$.

\section{Scatchard plots of fluorescence data}

Scatchard equation [28] is used to describe the interaction between DNA and small molecules. Scatchard equation expresses the binding of AO-hsDNA in the presence of MB-Sm(III) complex. 
$r_{\mathrm{AO}} / \mathrm{C}_{\mathrm{AO}}=K\left(n-r_{\mathrm{AO}}\right)$

where $r_{\mathrm{AO}}$ refers to the molecular amount of bound $\mathrm{AO}$ to total nucleotide concentration, $\mathrm{C}_{\mathrm{AO}}$ is the concentrations of free AO, $n$ is the number of binding sites of hsDNA, $K$ is the intrinsic binding constant of AO-hsDNA. There are different concentrations of $\mathrm{Sm}(\mathrm{III})(\mathrm{MB})_{3}($ ratio $=$ $c_{\mathrm{Sm}(\mathrm{III}(\mathrm{MB}) 3} / c_{\mathrm{hsDNA}}$, ratio $=0.00,0.30,0.60,0.90$, respectively).

Generally, it is regarded as an intercalation-binding mode if the values of $n$ are same in the presence and absence of the inclusion complex, and it is regarded as a dis-intercalation binding mode if the values of $K$ are same in the presence and absence of the inclusion complex. And it is regarded as mix binding mode including non-intercalation and intercalation binding if both the values of $n$ and $K$ are changed. Two groups of buffers in the presence of $\mathrm{NaCl}$ and absence of $\mathrm{NaCl}$ as a contrast were constructed. The results are shown in Table 1 .

Table 1. Data of Scatchard Equation of the interaction between MB-Sm(III) complex and hsDNA.

\begin{tabular}{|l|l|l|l|l|l|}
\hline Cure & Ratio $=c_{\text {Sm(III)(MB) } 3} / c_{\text {DNA }}$ & $\mathrm{NaCl} \%$ & Scatchard & $\mathrm{K} /\left(\mathrm{M}^{-1}\right)$ & $\mathrm{n}$ \\
\hline \multirow{2}{*}{$\mathrm{a}$} & \multirow{2}{*}{0.00} & 5.00 & $-430.32 \mathrm{X}+5.91$ & 430.32 & 0.01373 \\
\cline { 3 - 6 } & & 0 & $-549.90 \mathrm{X}+6.91$ & 549.90 & 0.01257 \\
\hline \multirow{2}{*}{$\mathrm{b}$} & 0.30 & 5.00 & $-732.72 \mathrm{X}+11.47$ & 732.72 & 0.01565 \\
\cline { 3 - 6 } & \multirow{2}{*}{0.60} & 0 & $-870.28 \mathrm{X}+15.04$ & 870.28 & 0.01728 \\
\hline \multirow{2}{*}{$\mathrm{c}$} & \multirow{2}{*}{0.90} & 5.00 & $-1296.37 \mathrm{X}+15.33$ & 1296.37 & 0.01182 \\
\cline { 3 - 6 } & & 0 & $-930.62 \mathrm{X}+19.74$ & 930.62 & 0.02121 \\
\cline { 3 - 6 } & & 0.00 & $-1497.55 \mathrm{X}+28.51$ & 1497.55 & 0.01904 \\
\hline
\end{tabular}

From Table 1, it can be seen that both $n$ and $K$ change with the concentration of MB-Sm(III) complex change. The variation of the parameter $n$ and $K$ suggest a mix interaction herein. Normally, the values of $\mathrm{n}$ in the present of $\mathrm{NaCl}$ are lower than those in the absence of $\mathrm{NaCl}$, indicating there is an electrostatic interaction between small molecules and DNA. While in Table 1, the values of $\mathrm{n}$ in the present of $\mathrm{NaCl}$ are basically lower than those in the absence of $\mathrm{NaCl}$, and combined with the results of absorption spectral, we can confirm that there are electrostatic interaction and intercalation binding between the inclusion complex MB-Sm(III) complex and DNA [29].

The influence of $\mathrm{Na}_{3} \mathrm{PO}_{4}$ to the inclusion complex system

In order to further confirm whether there exist electrostatic interaction between MB-Sm(III) complex and hsDNA, we also conducted $\mathrm{Na}_{3} \mathrm{PO}_{4}$ experiment. With increasing the amounts of the $\mathrm{Na}_{3} \mathrm{PO}_{4}$, electrostatic interaction results in obviously changes of the spectrum [30]. We can see from Figure 9 that the emission spectrum of MB-Sm(III) complex presents an emission peak at $684 \mathrm{~nm}$, it decreased obviously with increasing the amounts of $\mathrm{Na}_{3} \mathrm{PO}_{4}$. Combined with scatchard method, the result suggests that MB-Sm(III) complex interacts with DNA by electrostatic interaction.

\section{Viscosity method}

Viscosity experiment is an effective tool to decide the binding mode of small molecules and DNA. Thus, to further explore the interaction between MB-Sm(III) complex and hsDNA, we carried out viscosity measurements. A classical intercalation model demands the space of adjacent base pairs to be large enough to accommodate the bound ligand and elongate the 
double helix, resulting in an increase of DNA viscosity [31]. A partial non-classical intercalation of the complex would reduce the DNA viscosity [32].

The changes in relative viscosity of hsDNA are shown in Figure 10. With increasing concentrations of MB-Sm(III) complex, the values of relative viscosity reduced with increasing the amounts of MB-Sm(III) complex. Combined with previous conclusions, the result further suggests that partial intercalation should be the interaction mode of MB-Sm(III) complex with DNA.

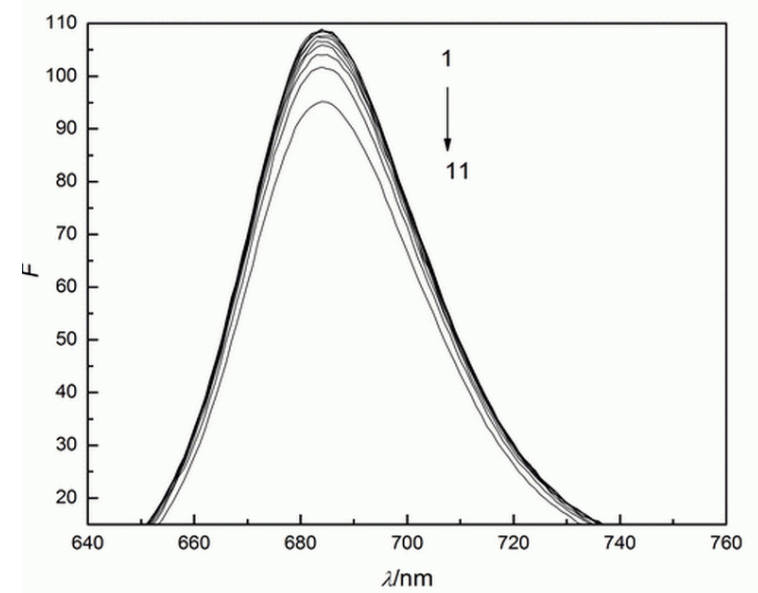

Figure 9. Effect of $\mathrm{Na}_{3} \mathrm{PO}_{4}$ on the fluorescence spectra of $\mathrm{Sm}(\mathrm{III})(\mathrm{MB})_{3} ; \mathrm{C}_{\mathrm{MB}-\mathrm{Sm}(\mathrm{III}) \text { complex }}=$ $1.00 \times 10^{-5} \mathrm{M}, \mathrm{C}_{\mathrm{Na} 3 \mathrm{PO} 4}=1.00 \times 10^{-3} \mathrm{M}(10 \mu \mathrm{L}$ per scan $\left.), 1-11: 0-100 \mu \mathrm{L} ; \mathrm{T}=292 \mathrm{~K}\right)$.

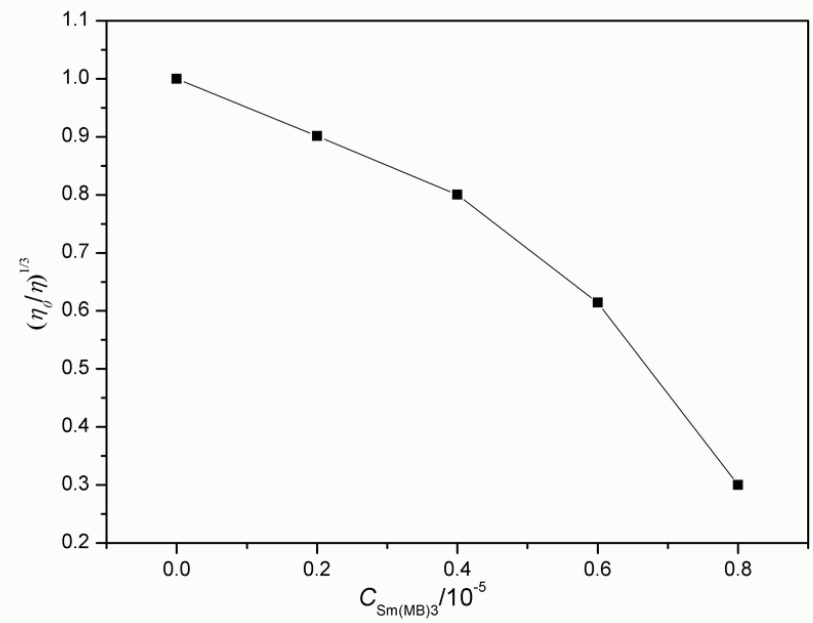

Figure 10. Variation of the relative viscosity of hsDNA $(\mathrm{pH}=7.40) ; \mathrm{C}_{\mathrm{hsDNA}}=2.00 \times 10^{-4} \mathrm{M} ; \mathrm{T}=$ $292 \mathrm{~K})$. 
Circular dichroism spectroscopy

Circular dichroism (CD) spectroscopy is a useful tool to diagnose changes in DNA morphology during drug-DNA interactions, since the positive band due to base stacking and the negative one due to right-handed helicity are quite sensitive to the interaction mode of DNA with small molecules [33]. Any change in the base stacking pattern or the helicity of the strands is manifested by either a change in the band position, the intensity, or both. A simple electrostatic interaction or groove binding has nearly no or a very insignificant effect on the band at $275 \mathrm{~nm}$, whereas the same band undergoes considerable change in intensity due to intercalation by small molecules $[34,35]$. The CD spectra of hsDNA in the presence of the MB-Sm(III) complex are shown in Figure 11. Obviously changes suggest that MB-Sm(III) complex interacts with hsDNA by intercalation binding. The observed decrease in the in the intensity of the band at $275 \mathrm{~nm}$ and at $248 \mathrm{~nm}$ is likely due to a transition from the extended nucleic acid double helix to the more compact C structure [35].

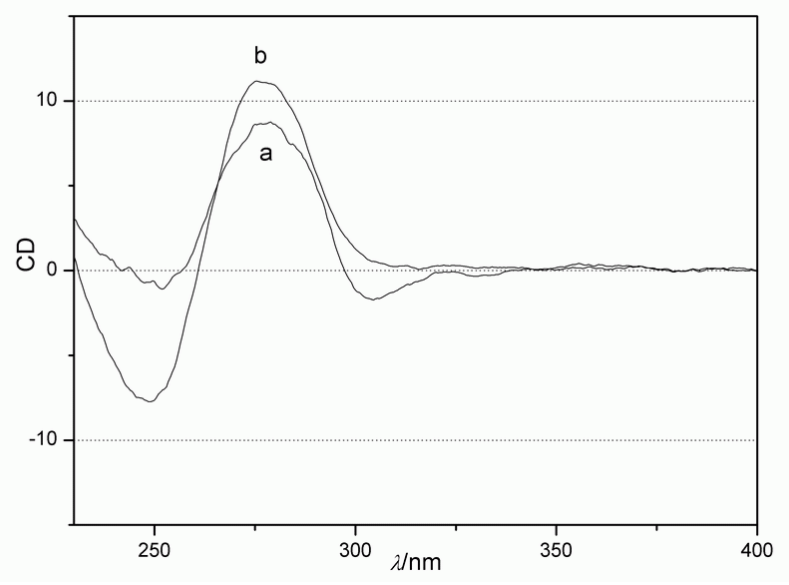

Figure 11. Sm(III)(MB $)_{3}$ complex effect on CD spectra of hsDNA; $a: \mathrm{C}_{\mathrm{hsDNA}}=1.00 \times 10^{-5} \mathrm{M}^{-1} ; \mathrm{b}$ : $\mathrm{C}_{\mathrm{MB}-\mathrm{Sm}(\mathrm{III}) \text { complex-hsDNA }}=1.00 \times 10^{-5} \mathrm{M}^{-1}, \mathrm{~T}=292 \mathrm{~K}$.

\section{CONCLUSIONS}

The interactions between the MB-Sm(III) complex and DNA have been investigated using UVVis spectra and fluorescence spectra. The quenching effect of MB-Sm(III) complex to hsDNAAO system indicated that the complex could substitute for AO in the hsDNA-AO system, there is intercalation mode between hsDNA and the complex. On the other hand, Scatchard analysis suggested there also exists electrostatic interaction, this issue was proved by $\mathrm{Na}_{3} \mathrm{PO}_{4}$ experiment. Furthermore, viscosity experiment confirmed that the intercalation mode is partial intercalation, which reduced the DNA viscosity, it was further supported by circular dichroism spectroscopy experiment. We calculated bonding constants between MB-Sm(III) complex and hsDNA, and thermodynamic function using double reciprocal method. These results strongly support the idea that MB-Sm(III) complex has important theoretical and practical value for the mechanism of drugs and drug design. 


\section{ACKNOWLEDGEMENTS}

This work was supported by the National Natural Science Foundation of China under Grant No. 30572254. We are grateful for the apparatus support of the Analytical and Testing Center of Southwest University of Science and Technology.

\section{REFERENCES}

1. Xu, M.; Ma, Z.R. Spectrochim. Acta, Part A 2011, 78, 503.

2. Facchin, G.; Kremer, E. Polyhedron 2009, 28, 2329.

3. Navarro, M.; Cisneros-Fajardo, E.J. J. Biol. Inorg. Chem. 2003, 8, 401.

4. He, X.Q.; Lin, Q.Y. Spectrochim. Acta, Part A 2007, 68, 184.

5. Gao, E.J.; Qing, W.; Wang, C.S. J. Coord. Chem. 2009, 21, 3425.

6. Partha, S.G.; Saurabh, D. J. Inorg. Biochem. 2009, 103, 1702.

7. Dutta, P.K., Hutt, J.A. Biochemistry 1986, 25, 691.

8. Li, J., Li, J.Y., Guo, Y.F. Chem. Res. 2005, 16, 101.

9. Hu, Z.; Tong, C.L. Anal. Chim. Acta 2007, 587, 187.

10. Li, X.B.; Zhou, A.R. J. Chin. Rare Earths Soc. 2000, $18,156$.

11. Chen, Z.F.; Tan, M.X.; Liu Y.C. J. Inorg. Biochem. 2011, 105, 308.

12. Wang, Y., Wang, Y., Zheng, Y.Y. Spectrochim. Acta, A 2007, 66, 329.

13. Li, Y.C., Yang, Z.Y., Zhang, K.J. Australian J. Chem. 2011, 64, 345.

14. Zhang, G.W.; Guo, J.B. Sens. Actuators, B 2010, 144, 239.

15. Erdem, A.; Kerman, K.; Meric, B. Electroanalysis 2001, 13, 219.

16. Mudasira, Wahyuni, E.T. Spectrochim. Acta, Part A 2010, 77, 528.

17. Alessio, T.; Giampaolo, B.; Arturo, S. J. Inorg. Biochem. 2009, 103, 1.

18. Kumar, R.S. Polyhedron 2007, 26, 3255.

19. Deng, Q.Y., Liu, L., Deng, H.M. Spectral Analysis Course, Science Publishing: Beijing; 2007.

20. Vaidyanathan, V.G. Eur. J. Inorg. Chem. 2003, 6, 3633.

21. Rabindranath, B.; Bijaya, K.S.; Kalyan, S. Int. J. Biol. Macromo. 2008, 142, 14.

22. Berman, H.M.; Young, P.R. Ann. Rev. Biophys. Bioeng. 1981, 10. 87.

23. Satyanarayana, S.; Dabrowiak, J.C.; Chaires, J.B. Biochem. 1993, 32, 2573.

24. Chen, Q.Y.; Huang, J. Spectrochim. Acta, Part A 2009, 72, 648.

25. Lyles, M.B.; Cameron, I.L. Biophys. Chem. 2002, 96, 53.

26. Shahabadi, N.; Kashanian, S.; Purfoulad. M. Spectrochim. Acta, Part A 2009, 72, 757.

27. Jing, B.W.; Zhang, M.H.; Shen. T. Spectrochim. Acta, Part A 2004, 60. 2635.

28. Torshizi, H.M.; Mital, R.; Srivastava, T.S. Inorg. Biochem. 1991, 44, 239.

29. Xu, D.L.; Wang, X.M. Carbohydrate Polymers 2011, 83, 1257.

30. Hu, Y.M.; Wang, X.M. Acta Chim Sinica 2008, 66, 1245.

31. Christiana, A.M.; Constantinos, E.D. Inorg. Chim. Acta 2008, 361, 1973.

32. Liu, Y.J.; Zeng, C.H. Transition Met. Chem. 2009, 34, 455.

33. Eleni, K.E.; Alexandra, K.; George, P. Polyhedron 2008, 27, 349.

34. Kasyanenko, N.A.; Zanina, A.V.; Nazarova, O.V. Langmuir 1999, 15, 7912.

35. Shahabadi, N.; Kashanian, S. DNA Cell Biol. 2009, 28, 589. 